Check for updates

Cite this: Chem. Commun., 2020, 56, 9557

Received 9th June 2020, Accepted 10th July 2020

DOI: $10.1039 / \mathrm{d} 0 \mathrm{cc} 04033 a$

rsc.li/chemcomm

\section{High-throughput characterisation of supramolecular gelation processes using a combination of optical density, fluorescence and UV-Vis absorption measurements $\dagger$}

\author{
Lisa J. White, ${ }^{a}$ Catherine Wark, ${ }^{b}$ Lorraine Croucher, ${ }^{b}$ Emily R. Draper (D) ${ }^{c}$ and \\ Jennifer R. Hiscock (D) *a
}

\begin{abstract}
Herein, we showcase the use of high-throughput microplate reader methodologies for the characterisation of supramolecular gels. We demonstrate how UV-Vis absorption, optical density and fluorescence measurements can selectively define gel fibre assembly/ disassembly processes, casting a new light on the construction of these materials.
\end{abstract}

Supramolecular gels are a class of soft material, formed through non-covalent interactions between the monomeric units of low molecular weight gelators. ${ }^{1}$ These monomeric units self-associate to produce a fibrous network, trapping any residual solvent. ${ }^{2}$ The scalability ${ }^{3}$ and regenerative properties ${ }^{4}$ has increased the popularity of these materials, making them of interest for a variety of applications which include chemosensors, ${ }^{5}$ biomedicines ${ }^{6}$ and drug delivery vehicles. ${ }^{7}$

To enable the characterisation and effective comparison of supramolecular organo/hydrogels, elucidation of a minimum gelation concentration through inversion testing is often obtained. ${ }^{8}$ In addition, a variety of other complementary techniques are often employed to confirm the presence, or further investigate the properties of the material. However, all these experimental techniques exhibit some limitations which include: the removal of solvent to produce a xerogel; expensive often specialised equipment; low potential for accurate data interpretation; large sample sizes; and/or long experimental time frames. Examples of these methods include the use of conventional UV-Vis absorption spectroscopy to identify organogel formation, ${ }^{9}$ dynamic light scattering to monitor fibre construction, ${ }^{10}$ rheology to observe bulk material properties, ${ }^{11}$ solution $^{12} / \mathrm{HRMAS}^{13} / \mathrm{solid}^{14}$ state NMR and confocal ${ }^{15}$ or fluorescence ${ }^{16}$ microscopy to observe the gel

\footnotetext{
${ }^{a}$ School of Physical Sciences, University of Kent, Canterbury, Kent, CT2 7NH, UK. E-mail: J.R.Hiscock@Kent.ac.uk; Tel: +44 (0)1227823043

${ }^{b}$ BMG Labtech, 8 Bell Business Park, Buckinghamshire, HP19 8JR, UK

${ }^{c}$ School of Chemistry, University of Glasgow, Glasgow, G12 8QQ, UK

$\dagger$ Electronic supplementary information (ESI) available: Experimental details, uniformity and validation experiments as well as absorbance, optical density and fluorescence data. See DOI: 10.1039/d0cc04033a
}

fibres in the native material state. Furthermore, transmission and scanning electron microscopy, ${ }^{17}$ in addition to powder X-ray diffraction techniques, ${ }^{18,19}$ have been used to define the structure of gel fibres obtained from xerogels. Finally, it has been shown that neutron diffraction techniques may be developed for selectively deuterated gels, ${ }^{19}$ to observe molecular packing arrangements in aggregated and gelated materials. ${ }^{20}$

Herein, we introduce a toolkit containing a series of highthroughput characterisation methods utilising microplate reader instrumentation. This methodology toolkit will be demonstrated using a molecular example from our extensively well characterised supramolecular self-associating amphiphile (SSA) systems. ${ }^{16,21}$ Use of this instrumentation for supramolecular gel characterisation affords: (i) low sample evaporation; (ii) in situ gel-sol/sol-gel measurement; (iii) low sample volume $\approx 200 \mu \mathrm{L}$; (iv) multiple experimental measurements per sample; (v) retention of sample integrity; and (vi) up to 384 experiments to be performed simultaneously. Additionally, we identify new properties of this model SSA gel, previously unobservable by traditional methodologies. ${ }^{16}$

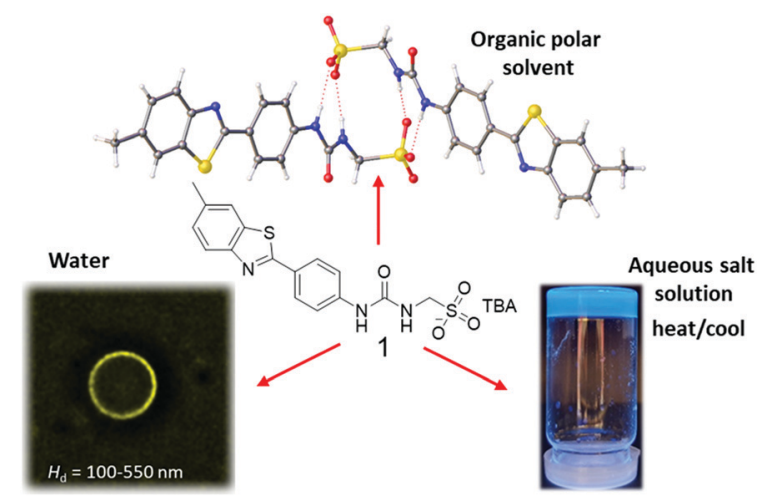

Fig. 1 Chemical structure of 1 and structures formed through the selfassociation of 1 (dimers, spherical aggregates and hydrogels) under different environmental conditions. TBA $=$ tetrabutylammonium. $H_{d}=$ hydrodynamic diameter. 
SSA 1 (Fig. 1) is an intrinsically fluorescent amphiphilic salt that has previously been shown to form anionic, hydrogen bonded dimeric species in DMSO ( $\approx 1.4 \mathrm{~nm}$ in diameter), ${ }^{21 b}$ spherical aggregates in $\mathrm{H}_{2} \mathrm{O}$ or $\mathrm{H}_{2} \mathrm{O}: \mathrm{EtOH}$ 19:1 mixtures ( $\approx 55-350 \mathrm{~nm}$ in diameter), ${ }^{21 b}$ and hydrogels in aqueous salt solutions. ${ }^{16}$ Within the toolkit produced here, we describe the use of UV-Vis absorption, optical density and fluorescence measurements for the selective study of supramolecular gel formation/solvation. To demonstrate the applicability of each method we present comparative data for $1\left(1.5 \mathrm{mg} \mathrm{mL}^{-1}\right)$ in DMSO, $\mathrm{H}_{2} \mathrm{O}$ and in two aqueous salt solutions $(\mathrm{NaCl}$ and $\mathrm{Na}_{2} \mathrm{CO}_{3}$ at $0.505 \mathrm{M}$ ), where molecular self-association events result predominately in dimerization, spherical aggregates and gel or incomplete gel formation respectively.

Initially, we study the self-associative structures formed by 1 using UV-Vis absorbance microplate reader measurements over a range of temperatures from $25{ }^{\circ} \mathrm{C}$ to $45{ }^{\circ} \mathrm{C}$. Fig. 2 shows those results obtained for a solution of 1 containing: (a) anionic dimers; (b) spherical aggregates; (c) a hydrogel; (d) an incomplete hydrogel. Here, as for all UV-Vis, optical density and fluorescence microplate reader studies detailed within this work, the type of self-associated structure (dimer, spherical aggregate or gel fibre) present within the sample studied was verified through comparison with published bulk material/ solution data. ${ }^{16,21 b, c}$ For that sample containing the selfassociated dimer (Fig. 2a) or spherical aggregate form of 1 (Fig. 2b), when heated from $25{ }^{\circ} \mathrm{C}$ to $45{ }^{\circ} \mathrm{C}$ no observable difference between spectra was observed. Although, we know from previous studies that these self-associated spherical aggregates are destabilised at temperatures $>40{ }^{\circ} \mathrm{C}$. ${ }^{21 b}$ However, where a hydrogel or incomplete hydrogel of $\mathbf{1}$ is known to form (Fig. 2c and d respectively) we observe an increase in absorbance at $450 \mathrm{~nm}$ (Abs.450). Comparing the Abs.450 values for spectra shown in Fig. 2, we see they remain $\leq 0.03 \mathrm{AU}$ for those solutions with no gel fibres present. However, where gel fibres are known to form - in the presence of $\mathrm{NaCl}$ (Fig. 2c) or $\mathrm{Na}_{2} \mathrm{CO}_{3}$ (Fig. 2d) we record Abs. 450 values of $1.47 \mathrm{AU}$ and 1.21 $\mathrm{AU}$ respectively at $25{ }^{\circ} \mathrm{C}$. We hypothesise that these higher Abs. 450 values are due to the presence of gel fibres that can absorb this wavelength and/or cause the observable scattering of the incident light. Interestingly, as the sample containing the incomplete hydrogel is heated to $45{ }^{\circ} \mathrm{C}$, the Abs. ${ }_{450}$ value is found to decrease by $\approx 50 \%$ to $0.61 \mathrm{AU}$. This same decrease in Abs. ${ }_{450}$ value is not observed for the $\mathrm{NaCl}$ containing hydrogel, which was only found to decrease to $1.37 \mathrm{AU}$ at $45^{\circ} \mathrm{C}$. Consequently, we hypothesise that the fibrous structures of $1\left(1.5 \mathrm{mg} \mathrm{mL}^{-1}\right)$ disassemble, in the case of the incomplete hydrogel (Fig. 2d) however, remain stable in the case of the hydrogel (Fig. $2 \mathrm{c}$ ) at $45{ }^{\circ} \mathrm{C}$. It is, therefore, possible that comparison of these Abs. 450 measurements may also be used to estimate the proportional amount of gel fibres present within a given sample at a particular temperature.

As shown, these UV-Vis Abs. ${ }_{450}$ measurements could be used to verify the presence of gel fibres within a sample of $\mathbf{1}$ (Abs. . $_{40}>$ $0.05 \mathrm{AU}$ ), when compared to other self-associated species such as dimers or spherical aggregates (Abs.450 $<0.05$ AU) at comparable concentrations within a microplate well. We next explored the use of optical density measurements at $450 \mathrm{~nm}\left(\mathrm{OD}_{450}\right)$ to further characterise this system. Spectral scanning experiments performed for those same samples of $\mathbf{1}$ as shown in Fig. 2, allow us to further observe any self-associated structures of 1 within a microplate well, over a $25{ }^{\circ} \mathrm{C}$ to $45{ }^{\circ} \mathrm{C}$ temperature range. Here, as shown in Fig. 3, the surface area of each well was divided into 177 sections, with an $\mathrm{OD}_{450}$ measurement obtained for each. When only small dimeric self-associated species are known to exist (Fig. 3a) $\mathrm{OD}_{450}$ measurements obtained for each section of the microplate well are shown to be uniformly low. However, moving into $\mathrm{H}_{2} \mathrm{O}$ only (Fig. 3b), we observe evidence of 1 primarily self-associating at the microplate well periphery. Amphiphilic compounds such as 1, that are shown to lower the surface tension of aqueous solutions, ${ }^{21}$ are known to preferentially self-associate at the interface until the critical micelle concentration (CMC) is reached. ${ }^{22}$ Therefore, by observing and/ or comparing the $\mathrm{OD}_{450}$ spectral scan data, it is possible to observe any self-associated structures of 1 existing at the interface as opposed to those spherical aggregates which exist in the bulk solution. This is indicated by the comparatively high $\mathrm{OD}_{450}$ measurements recorded at the periphery of the microplate well over the central regions. Where gel fibres are known
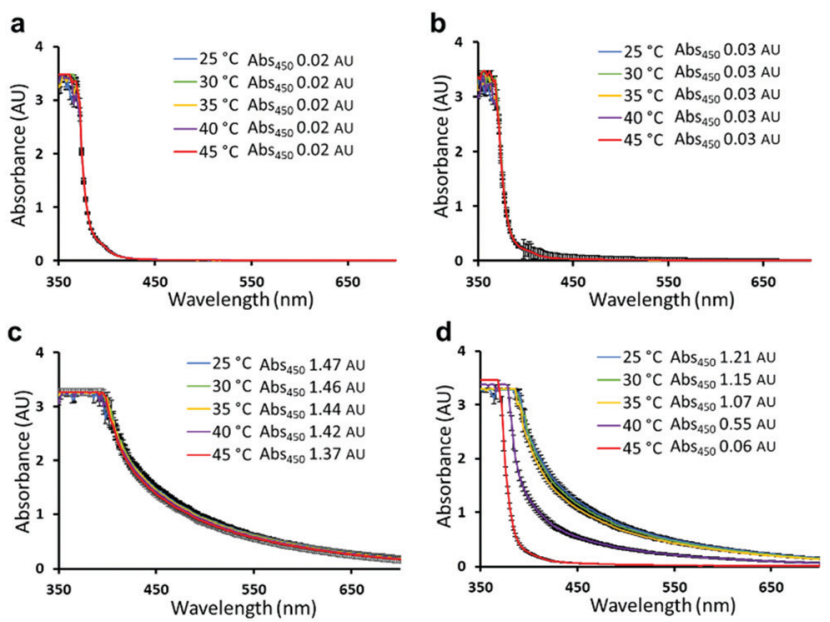

Fig. 2 Average $(n=3)$ absorbance spectra of $1\left(200 \mu \mathrm{L}, 1.5 \mathrm{mg} \mathrm{mL}^{-1}\right)$ in; (a) DMSO; (b) $\mathrm{H}_{2} \mathrm{O}$; (c) $\mathrm{NaCl}(0.505 \mathrm{M})$; (d) $\mathrm{Na}_{2} \mathrm{CO}_{3}$ (0.505 M). Volume and concentration measurements result in saturation at 3.5 OD for wavelengths $<400 \mathrm{~nm}$. Error bars represent the full range of absorbance measurements obtained for $n=3$ measurements.
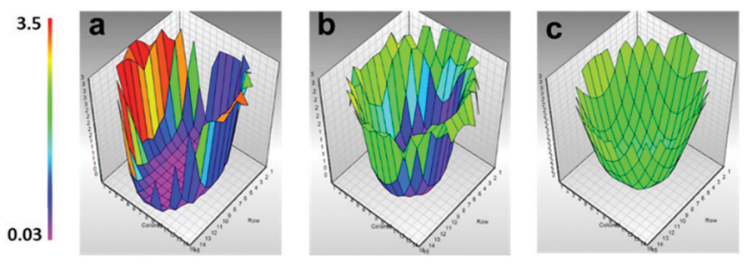

Fig. 3 Spectral analysis well scans conducted at $\mathrm{OD}_{450}$ with $1\left(1.5 \mathrm{mg} \mathrm{mL}^{-1}\right)$ at $25^{\circ} \mathrm{C}$ in; (a) DMSO; (b) $\mathrm{H}_{2} \mathrm{O}$; and (c) $\mathrm{NaCl}(0.505 \mathrm{M})$. High $\mathrm{OD}_{450}=$ red. Low $\mathrm{OD}_{450}=$ purple. Each segment (outlined in black) represents a different portion of an individual microplate well as each measurement is recorded for the entire depth of the sample. 
to form (Fig. 3c), uniformly higher $\mathrm{OD}_{450}$ measurements are recorded across the entirety of the microplate well.

To further enable the analysis of these spectral scan data, two-dimensional $\mathrm{OD}_{450}$ maps were also produced (Fig. 4). This representation of those data shown in Fig. 3 demonstrates lower $\mathrm{OD}_{450}$ values occurring towards the centre of the well, with higher values towards the periphery, where $\mathbf{1}$ is present as a hydrogel or incomplete hydrogel (Fig. 4a and b). As for those Abs. 450 measurements (Fig. 2c and d), we observed no notable change for these data displayed within the intensity map produced for the hydrogel of $\mathbf{1}$ containing $\mathrm{NaCl}$ as the temperature was raised from $25{ }^{\circ} \mathrm{C}$ to $45{ }^{\circ} \mathrm{C}$. However, for the incomplete hydrogel formed in the presence of $\mathrm{Na}_{2} \mathrm{CO}_{3}$, we observe a decrease in $\mathrm{OD}_{450}$ values across the majority of the 177 microplate well segments with increasing temperature. Through ratioing the $\mathrm{OD}_{450}$ maximum and minimum values (the highest and lowest OD values recorded for a single well of a single sample at a single temperature) Table 1, it becomes possible to screen these data for the presence/amount of gel fibres, validated by those previously published data for the 'bulk' material summarised in Table 2, and obtain a gel-sol/gel fibre melting temperature $\left(T_{\mathrm{m}}\right)$, as illustrated in Fig. 5. This proof-ofprinciple dataset indicates that at a ratio value $<0.06$, unless the material is uniformly gelled, proportionally very few if any gel fibres will be present. Here, 1 instead acts as an amphiphile, with only extensive self-associated structures observable at the
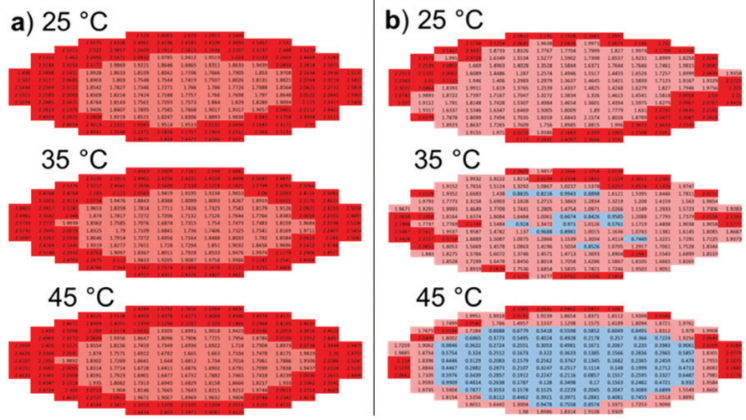

Fig. $4 \mathrm{OD}_{450}$ intensity maps produced for 1 (1.5 $\mathrm{mg} \mathrm{mL}^{-1}$ in): (a) $\mathrm{NaCl}$ $(0.505 \mathrm{M})$ where the bulk sample is known to form a hydrogel at $25^{\circ} \mathrm{C}$; and (b) $\mathrm{Na}_{2} \mathrm{CO}_{3}(0.505 \mathrm{M})$ where the bulk sample is known to form an incomplete hydrogel at $25^{\circ} \mathrm{C}$. Blue: $\mathrm{OD}_{450}=0.00-0.99 \mathrm{AU}$. Pink: $\mathrm{OD}_{450}=1.00-1.99 \mathrm{AU}$. Red: $\mathrm{OD}_{450}=2.00-3.00 \mathrm{AU}$. Each segment (outlined in black) represents a different portion of the microplate well as each individual measurement is recorded for the entire depth of the sample (top to bottom).

Table 1 Average $(n=3)$ ratio values $\left(\mathrm{OD}_{450}\right.$ maximum/OD 450 minimum) taken from the spectra well scan data of $1\left(200 \mu \mathrm{L}, 1.5 \mathrm{mg} \mathrm{mL}^{-1}\right)$ in DMSO, $\mathrm{H}_{2} \mathrm{O}$ and various aqueous salt solutions (soln) $(0.505 \mathrm{M})$ at various temperatures $\left({ }^{\circ} \mathrm{C}\right)$

\begin{tabular}{|c|c|c|c|c|c|c|c|c|}
\hline \multirow[b]{2}{*}{ Soln } & \multicolumn{2}{|c|}{ Temperature } & \multirow[b]{2}{*}{ Soln } & \multicolumn{2}{|c|}{ Temperature } & \multirow[b]{2}{*}{ Soln } & \multicolumn{2}{|c|}{ Temperature } \\
\hline & 25 & 45 & & 25 & 45 & & 25 & 45 \\
\hline DMSO & 0.01 & 0.02 & $\mathrm{Na}_{2} \mathrm{CO}_{3}$ & 0.35 & 0.05 & $\mathrm{NaF}$ & 0.55 & 0.48 \\
\hline $\mathrm{H}_{2} \mathrm{O}$ & 0.02 & 0.02 & $\mathrm{Na}_{2} \mathrm{SO}_{4}$ & 0.62 & 0.56 & $\mathrm{NaCl}$ & 0.63 & 0.59 \\
\hline $\mathrm{Na}_{2} \mathrm{HPO}_{4}$ & 0.31 & 0.03 & $\mathrm{NaHCO}_{3}$ & 0.57 & 0.48 & $\mathrm{NaNO}_{3}$ & 0.62 & 0.60 \\
\hline $\mathrm{NaH}_{2} \mathrm{PO}_{4}$ & 0.55 & 0.05 & NaOAc & 0.70 & 0.65 & $\mathrm{NaOBz}$ & 0.64 & 0.58 \\
\hline
\end{tabular}

Table 2 Average $(n=3) T_{\mathrm{m}}\left({ }^{\circ} \mathrm{C}\right)$ for hydrogels of $1\left(5 \mathrm{mg} \mathrm{mL}^{-1}\right)$ and $T_{\mathrm{fa}}\left({ }^{\circ} \mathrm{C}\right)$ obtained for a hydrogels/incomplete hydrogels of $1\left(1.5 \mathrm{mg} \mathrm{mL}^{-1}\right)$ in an aqueous salt solution $(0.505 \mathrm{M})$. Mat. prop. = material property of 1 $\left(1.5 \mathrm{mg} \mathrm{mL}^{-1}\right)$ in DMSO, $\mathrm{H}_{2} \mathrm{O}$ or aqueous salt solutions $(0.505 \mathrm{M})$ at $25^{\circ} \mathrm{C}$ ( $n=$ no gel, $\mathrm{i}=$ incomplete gel, $\mathrm{g}=$ gel)

\begin{tabular}{llllllll}
\hline Soln & $T_{\mathrm{m}}{ }^{16}$ & $T_{\mathrm{fa}}$ & Mat. prop. & Soln & $T_{\mathrm{m}}{ }^{16}$ & $T_{\mathrm{fa}}$ & Mat. Prop. \\
\hline $\mathrm{Na}_{2} \mathrm{HPO}_{4}$ & $\mathrm{i}$ & $<25$ & $\mathrm{i}$ & $\mathrm{NaOAc}$ & 46 & $>45$ & $\mathrm{i}$ \\
$\mathrm{NaH}_{2} \mathrm{PO}_{4}$ & 44 & $40-45$ & $\mathrm{~g}$ & $\mathrm{NaF}$ & 47 & $>45$ & $\mathrm{i}$ \\
$\mathrm{Na}_{2} \mathrm{CO}_{3}$ & 43 & $40-45$ & $\mathrm{i}$ & $\mathrm{NaCl}$ & 51 & $>45$ & $\mathrm{~g}$ \\
$\mathrm{Na}_{2} \mathrm{SO}_{4}$ & 43 & $>45$ & $\mathrm{i}$ & $\mathrm{NaNO}_{3}$ & 52 & $>45$ & $\mathrm{~g}$ \\
$\mathrm{NaHCO}_{3}$ & 45 & $>45$ & $\mathrm{i}$ & $\mathrm{NaOBz}$ & 54 & $>45$ & $\mathrm{~g}$
\end{tabular}

Experimental $T_{\mathrm{m}}$ and $T_{\mathrm{fa}}$ details are provided within the ESI for convenience.

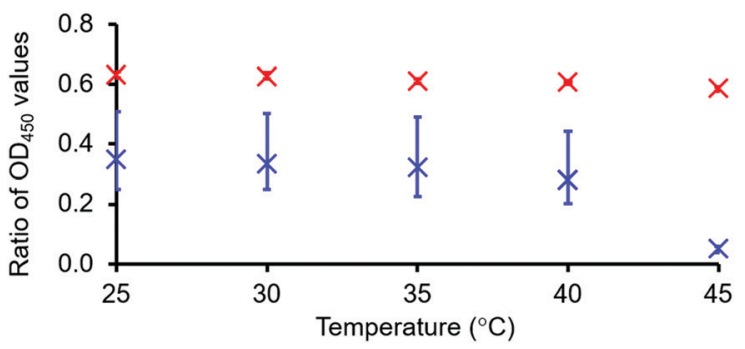

Fig. 5 Average $(n=3)$ ratio values $\left(\mathrm{OD}_{450}\right.$ maximum $/ \mathrm{OD}_{450}$ minimum) taken from the spectra well scan data of $1\left(1.5 \mathrm{mg} \mathrm{mL}^{-1}\right)$ in aqueous salt solutions $(0.505 \mathrm{M})$ of $\mathrm{NaCl}$ (red) and $\mathrm{Na}_{2} \mathrm{CO}_{3}$ (blue). Error bars represent the full range of $O D_{450}$ ratio values to be calculated from the $n=3 O_{450}$ maxima and minimum data.

microplate well interface. This data also suggests there is a different density of structures and/or different structures present at the surface-gel interface, as reported previously by Marlow and Zelzer. ${ }^{23}$

Due to the intrinsic fluorescent nature of $\mathbf{1}$, we were also able to investigate the self-assembly processes of this SSA using fluorescence spectroscopy. Interestingly, although this method was able to distinguish between the presence of dimers (Fig. 6a) and larger self-associated aggregates (Fig. 6b-d). This method could not verify the presence of spherical aggregates (Fig. 6b) over gel fibres (Fig. 6c and d), due to the lack of distinguishing spectral features observed for these samples. However, comparison of emission profiles we are able to follow the disassembly of those larger self-associated structures formed with increasing temperature (Fig. 6b and d). Here the disassembly process can be identified through increasing intensity of the emission spectrum maxima when excited at $435 \mathrm{~nm}$. The lack of change in the emission spectra of that sample shown in Fig. $6 \mathrm{c}$ is due to the $T_{\mathrm{m}}$ for this sample being $>45{ }^{\circ} \mathrm{C}$. We hypothesise that both the decrease in experimental sensitivity towards aggregate identification and observation of the aggregate disassembly process can be explained as a result of incident light scattering by the sample.

Finally, we detail the additional self-associative system information generated for $\mathbf{1}$ using this combination of plate reader methodologies, unobtainable through our previous characterisation of these systems. ${ }^{16}$ As shown in Table 2 when supplied at a concentration of $5 \mathrm{mg} \mathrm{mL}^{-1}, 1$ gelated all salt 
a
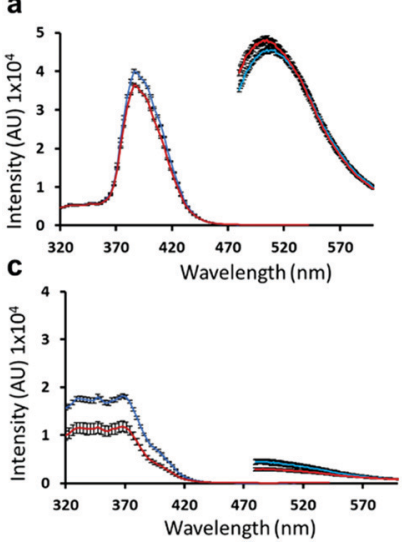

Fig. 6 Average ( $n=3$ ) fluorescence excitation (left) and emission (right) spectra of $1\left(200 \mu \mathrm{L}, 1.5 \mathrm{mg} \mathrm{mL}^{-1}\right)$ at $25^{\circ} \mathrm{C}$ (blue) and $45^{\circ} \mathrm{C}$ (red) in: (a) DMSO; (b) $\mathrm{H}_{2} \mathrm{O}$; (c) aqueous $\mathrm{NaCl}\left(0.505 \mathrm{M}\right.$ ); (d) aqueous $\mathrm{Na}_{2} \mathrm{CO}_{3}$ $(0.505 \mathrm{M})$. Error bars represent the full range of fluorescence spectroscopy measurements for three repetitions.

solutions listed, apart from $\mathrm{Na}_{2} \mathrm{HPO}_{4}$. This enabled the elucidation of comparative gel-sol $T_{\mathrm{m}}$ values. However, those same samples presented to the microplate reader for analysis proved too concentrated for accurate measurements to be obtained. For this reason, in the case of these microplate reader studies, the concentration of 1 was reduced to $1.5 \mathrm{mg} \mathrm{mL} \mathrm{m}^{-1}$ for all samples. This resulted in a mixture of gels, incomplete gels and solutions. However, as confirmed by the results of both comparative UV-Vis absorption and optical density measurements, the fibre assembly temperature range $\left(T_{\mathrm{fa}}\right)$ calculated using these methods at $1.5 \mathrm{mg} \mathrm{mL}{ }^{-1}$ was found to correlate with the results of gel-sol $T_{\mathrm{m}}$ studies conducted at $5 \mathrm{mg} \mathrm{mL}{ }^{-1}$. This leads us to hypothesise that the $T_{\mathrm{m}}$ is not only representative of the gel-sol transition temperature but also gelator monomer dissociation, resulting in fibre solvation and is concentrationindependent between 1.5 and $5.0 \mathrm{mg} \mathrm{mL} \mathrm{m}^{-1}$. Additionally, the $\mathrm{OD}_{450}$ intensity maps produced for hydrogels/incomplete hydrogels of 1 show a greater proportion of gel fibres to exist at the sample periphery in comparison to the well interior, giving us new information about material formation and construction.

We have introduced a toolkit of high-throughput gel characterisation methods using microplate reader technology. It is envisioned that this toolkit maybe used for standard supramolecular gel characterisation, removing those limitations overviewed herein. Using UV-Vis absorption measurements we have shown that for solutions/gels/incomplete hydrogels of $\mathbf{1}$, increased Abs. 450 values selectively indicate gel fibre formation. $\mathrm{OD}_{450}$ measurements may also be used to selectively observe the formation of gel fibres. Interestingly, spectral well-scans confirmed SSA self-assembly processes at the interface in the presence and absence of gel fibre formation in aqueous solutions. The use of the well scan measurements could be used to illustrate uniformity of gelation or be used to characterise gel patterning or gradients. This would be a huge advantage as it is non-destructive and is carried out in-situ. We also established that although fluorescence spectroscopy is an incredibly sensitive technique for molecular/complex characterisation, here this technique is unable to reliably distinguish between spherical aggregate and gel fibre formation. Finally, we propose that the $T_{\mathrm{m}}$ of a supramolecular gel may be due to fibre disassembly and therefore concentration-independent to the point of solution saturation, although verification of this hypothesis remains the subject of ongoing investigation.

\section{Conflicts of interest}

There are no conflicts to declare.

\section{References}

1 J. W. Steed, Chem. Commun., 2011, 47, 1379-1383.

2 P. R. A. Chivers and D. K. Smith, Nat. Rev. Mater., 2019, 4, 463-478.

3 B. O. Okesola and D. K. Smith, Chem. Soc. Rev., 2016, 45, 4226-4251.

4 Z. Yang, G. Liang, Z. Guo, Z. Guo and B. Xu, Angew. Chem., Int. Ed., 2007, 46, 8216-8219.

5 Q. Lin, T.-T. Lu, X. Zhu, B. Sun, Q.-P. Yang, T.-B. Wei and Y.-M. Zhang, Chem. Commun., 2015, 51, 1635-1638.

6 L. Yu and J. Ding, Chem. Soc. Rev., 2008, 37, 1473.

7 C. Liu, C. Ruan, R. Shi, B.-P. Jiang, S. Ji and X.-C. Shen, Biomater. Sci., 2019, 7, 1705-1715.

8 G. Yu, X. Yan, C. Han and F. Huang, Chem. Soc. Rev., 2013, 42, 6697-6722.

9 O. Kotova, R. Daly, C. M. G. dos Santos, M. Boese, P. E. Kruger, J. J. Boland and T. Gunnlaugsson, Angew. Chem. Int. Ed., 2012, 51, 7208-7212.

10 X. Liao, G. Chen, X. Liu, W. Chen, F. Chen and M. Jiang, Angew. Chem. Int. Ed., 2010, 122, 4511-4515.

11 E. R. Draper, E. G. B. Eden, T. O. McDonald and D. J. Adams, Nat. Chem., 2015, 7, 848-852.

12 B. Escuder, M. Llusar and J. F. Miravet, J. Org. Chem., 2006, 71, 7747-7752.

13 S. Iqbal, F. Rodríguez-LLansola, B. Escuder, J. F. Miravet, I. Verbruggen and R. Willem, Soft Matter, 2010, 6, 1875-1878.

14 N. Nonappa and E. Kolehmainen, Soft Matter, 2016, 12, 6015-6026.

15 M. Ahearne, Y. Yang, A. J. El Haj, K. Y. Then and K. K. Liu, J. R. Soc., Interface, 2005, 2, 455-463.

16 L. J. White, J. E. Boles, N. Allen, L. S. Alesbrook, J. M. Sutton, C. K. Hind, K. L. F. Hilton, L. R. Blackholly, R. J. Ellaby, G. T. Williams, D. P. Mulvihill and J. R. Hiscock, J. Mater. Chem. B, 2020, 8, 4694-4700.

17 N. S. S. Kumar, S. Varghese, G. Narayan and S. Das, Angew. Chem., Int. Ed., 2006, 45, 6317-6321.

18 S. Basak, J. Nanda and A. Banerjee, J. Mater. Chem., 2012, 22, 11658.

19 V. A. Mallia, P. Terech and R. G. Weiss, J. Phys. Chem. B, 2011, 115, 12401-12414.

20 E. R. Draper, B. Dietrich, K. McAulay, C. Brasnett, H. Abdizadeh, I. Patmanidis, S. J. Marrink, H. Su, H. Cui, R. Schweins, A. Seddon and D. J. Adams, Matter, 2020, 2, 764-778.

21 (a) G. Townshend, G. S. Thompson, L. J. White, J. R. Hiscock and J. L. Ortega-Roldan, Chem. Commun., 2020, 56, 4015-4018; (b) L. J. White, N. J. Wells, L. R. Blackholly, H. J. Shepherd, B. Wilson, G. P. Bustone, T. J. Runacres and J. R. Hiscock, Chem. Sci., 2017, 8, 7620-7630; (c) L. J. White, S. N. Tyuleva, B. Wilson, H. J. Shepherd, K. K. L. Ng, S. J. Holder, E. R. Clark and J. R. Hiscock, Chem. - Eur. J., 2018, 24, 7761-7773.

22 D. Chandler, Nature, 2005, 437, 640-647.

23 M. G. F. Angelerou, A. Sabri, R. Creasey, P. Angelerou, M. Marlow and M. Zelzer, Chem. Commun., 2016, 52, 4298-4300. 